\title{
РАЗВИТИЕ ТВОРЧЕСКИХ СПОСОБНОСТЕЙ МЛАДШИХ ШКОЛЬНИКОВ В ПРОЦЕССЕ ПРЕПОДАВАНИЯ ПРОГРАММ КОНСТРУИРОВАНИЯ И МОДЕЛИРОВАНИЯ ХУДОЖЕСТВЕННЫХ ОБРАЗОВ ЧЕРЕЗ СОЗДАНИЕ МУЛЬТФИЛЬМОВ
}

\section{DEVELOPMENT OF CREATIVE ABILITIES OF YOUNGER STUDENTS IN THE PROCESS OF TEACHING PROGRAMS DESIGNING AND MODELING ARTISTIC IMAGES THROUGH THE CREATION OF CARTOONS}

A. Morozova

Summary: The Relevance of the problem, its theoretical and practical significance, as well as the lack of development determined the choice of the research topic and its methodological apparatus. The scientific task of the research is to develop the creative abilities of younger students in the process of teaching programs for designing and modeling artistic images through the creation of cartoons. The purpose of the research is to create a program for designing and modeling artistic images in the process of creating cartoons in the system of additional education, which provides the development of creative abilities of younger students. The object of the research is the educational activity of educational institutions of additional education in schools. The subject of the research is the process of developing creative abilities of students in the process of teaching programs for designing and modeling artistic images through the creation of cartoons. As research methods, an analytical method was used to analyze the literature on the problem of developing creative abilities, generalization, study of design programs for primary school age, study of animation programs, and design. It is also an empirical method, expressed in a survey, questionnaire, or observation. The paper presents the conceptual apparatus of the categories: design, technical and artistic design, modeling, animation.

Keywords: creative abilities, development, technical design, artistic design, modeling, animation.
Морозова Анна Алексеевна

Московский городской педагогический университет; педагог-организатор, ГБОУ г. Москвы «Школа № 1370» annana2007@yandex.ru

Аннотация: Актуальность проблемы, ее теоретическая и практическая значимость, а также недостаточная разработанность определили выбор темы исследования и его методологический аппарат. Научная задача исследования состоит в развитии творческих способностей младших школьников в процессе преподавания программ конструирования и моделирования художественных образов через создание мультфильмов. Целью исследования является создание программы конструирования и моделирования художественных образов в процессе создания мультфильмов в системе дополнительного образования, обеспечивающую развитие творческих способностей младших школьников. Объектом исследования в работе выступает учебно-воспитательная деятельность образовательных учреждений дополнительного образования в школе. Предмет исследования - процесс развития творческих способностей учащихся в процессе преподавания программ конструирования и моделирования художественных образов через создание мультфильмов. В качестве методов исследования применялся аналитический метод для проведения анализа литературы по проблеме развития творческих способностей, обобщение, изучение программ по конструированию для младшего школьного возраста, изучение программ по мультипликации, проектирование. Также и эмпирический метод, выраженный в опросе, анкетировании, наблюдении. В работе приводится понятийный аппарат категорий: конструирование, техническое и художественное конструирование, моделирование, мультипликация.

Ключевые слова: творческие способности, развитие, техническое конструирование, художественное конструирование, моделирование, мультипликация.

их надо развивать.

Просмотр телевидения, видеофильмов, компьютерные игры, мобильные телефоны становятся привычной формой досуга. Как совместить несовместимое?

Конструирование и просмотр мультфильмов?

В современном мире информационные компьютерные технологии все больше входят в жизнь и сознание ребенка. Прогресс остановить невозможно, значит им надо пользоваться так, чтобы детям это было не только 
интересно, но и развивало его творческий и интеллектуальный потенциал. Сделать технические студии более творческими - эта проблема натолкнула меня на исследование развития творческих способностей детей младшего школьного возраста в процессе преподавания программ конструирования и моделирования художественных образов через создание мультфильмов.

Творческие способности - способности человека принимать творческие решения, принимать и создавать принципиально новые идеи.

В повседневной жизни творческие способности проявляются как смекалка - способность достигать цели, находить выход из кажущейся безвыходной ситуации, используя обстановку, предметы и обстоятельства необычным образом.

В широком смысле - нетривиальное и остроумное решение проблемы, причём, как правило, неспециализированными инструментами или ресурсами. Имеется также в виду способность к смелым, нестандартным решениям проблем.

Конструирование - это продуктивный вид деятельности ребенка, направленный на создание определенного предмета - «построение, создание модели». Существует два типа детского конструирования: техническое и художественное.

Техническое конструирование - это процесс создания ребенком предметов, которые он уже видел в реальной жизни или представляет их в своем воображении: машина с дверью, капотом, прицепом; дом с крышей, дверью, окном.

Художественное конструирование - это творческий процесс, в котором главную роль играет не структура предмета, а отношение ребенка к нему.

Детское конструирование включает такие элементы профессионального конструирования как обдумывание, осмысливание идеи, создание мысленного образа, определение последовательности изготовления изделия, набор необходимых материалов и инструментов.

Важным моментом конструирования является тот факт, что в процессе работы детям постоянно приходится решать самые разнообразные конструкторские задачи. Решение таких задач активизирует мыслительную деятельность и способствует формированию зачатков технического и технологического мышления.

Моделирование - создание образа (в том числе условного или умозрительного - изображение, описание, схема, чертеж, график, план, карта и т.д.)
Мультфильм-мультипликация, анимация, мультипликационное кино - вид киноискусства, произведения которого создаются путем съемки последовательных фаз движения рисованных (графическая или рисованная мультипликация) или объёмных (объёмная или кукольная мультипликация) объектов.

Мультипликация - (от лат. Multiplication - умножение, увеличение, возрастание, размножение) или анимация (от фр. Animation - оживление, одушевление) означает оживление и одушевление нарисованного или смоделированного персонажа мультфильма.

«Формирование знаний медиапользования у школьников - неотъемлемая часть современного образовательного процесса. Этот вопрос не один год изучают такие педагоги как Л.М. Баженова, Ю.Н. Усов, А.В. Федоров и др.

Педагогический процесс на сегодняшний день характеризуется применением современных образовательных технологий, что помогает открывать новые возможности, стимулировать интерес к учебе, повышать мотивацию, увеличивать эффективность самостоятельной и групповой работы, а, следовательно, развивать творческие способности детей.

Младшие школьники чаще всего воспринимают и усваивают информацию через визуальные образы, поэтому мультипликация - для них самый доступный способ получения информации. Есть простая форма работы с мультфильмами - просмотр. Однако в таком случае информация, которую хочет донести до зрителя создатель мультфильма, скорее всего не усвоится или легко забудется. Более трудоемкая форма работы - создание мультфильма. Создавая мультфильм, ребенок сам является создателем и сам несет какую-то информацию. Создавая мультфильм, дети оказываются в центре творческого процесса. Создавая мультфильм - дети развиваются в различных областях - литература (написание сценария), рисование, лепка, конструирование (декорации, персонажи), музыка (музыкальное сопровождение), речь (озвучивание персонажей), техника (работа с компьютером, фото/видеоаппаратурой).

В целом создание мультипликационных фильмов состоит из нескольких этапов:

- продумывание сценария (подбор музыкального сопровождения, выбор материала и приема работы);

- работа над декорациями, персонажами и съемочными материалами;

- съемочный процесс;

- монтаж;

- презентация творческой работы активно стиму- 
лирует творческий потенциал, а, следовательно, развивает творческие способности детей.

Итак, преподавание программ конструирования и моделирования художественных образов через создание мультфильмов позволяет естественным образом развивать творческие способности учащихся за счет решения творческих задач. При этом, с одной стороны, существует необходимость наличия у ребёнка творческого начала и опыта, с другой - осуществление подобной деятельности способствует его приобретению и развитию.

\section{ЛИТЕРАТУРА}

1. Конышева Н.М. Конструирование как средство развития младших школьников. М.: Флинт, 2000.88 с.

2. Богоявленская Д.Б. Психология творческих способностей. М.: Академия, 2002. - 352 с.

3. Выготский Л.С. Воображение и творчество в детском возрасте. М.: Просвещение, 1976. - 182 с.

4. Савлучинская Н.В., Щечилина А.В. Освоение мультипликации младшими школьниками в системе дополнительного образования как средство развития воображения // Гуманитарные исследования. 2017. - №4. - С. 125-128.

5. Казанцева В.А, Бухавецкая А.Ю. Развитие творческих способностей младших школьников в процессе выполнения творческих заданий // Новая наука: стратегии и векторы развития, 2016, № 118-2 . С. 63-66.

6. Дементьева С.В., Барциц Р.Ч. Развитие творческих способностей школьников средствами пластилиновой анимации в системе дополнительного образования // Наука и школа. 2019. №4. С. 193-198.

7. Савлучинская Н.В., Щечилина А.В. Освоение мультипликации младшими школьниками в системе дополнительного образования как средство развития воображения // Вестник Омского государственного педагогического университета. Гуманитарные исследования. 2017. №4 (17). С. 125 -128.

() Морозова Анна Алексеевна (annana2007@yandex.ru).
Журнал «Современная наука: актуальные проблемы теории и практики»

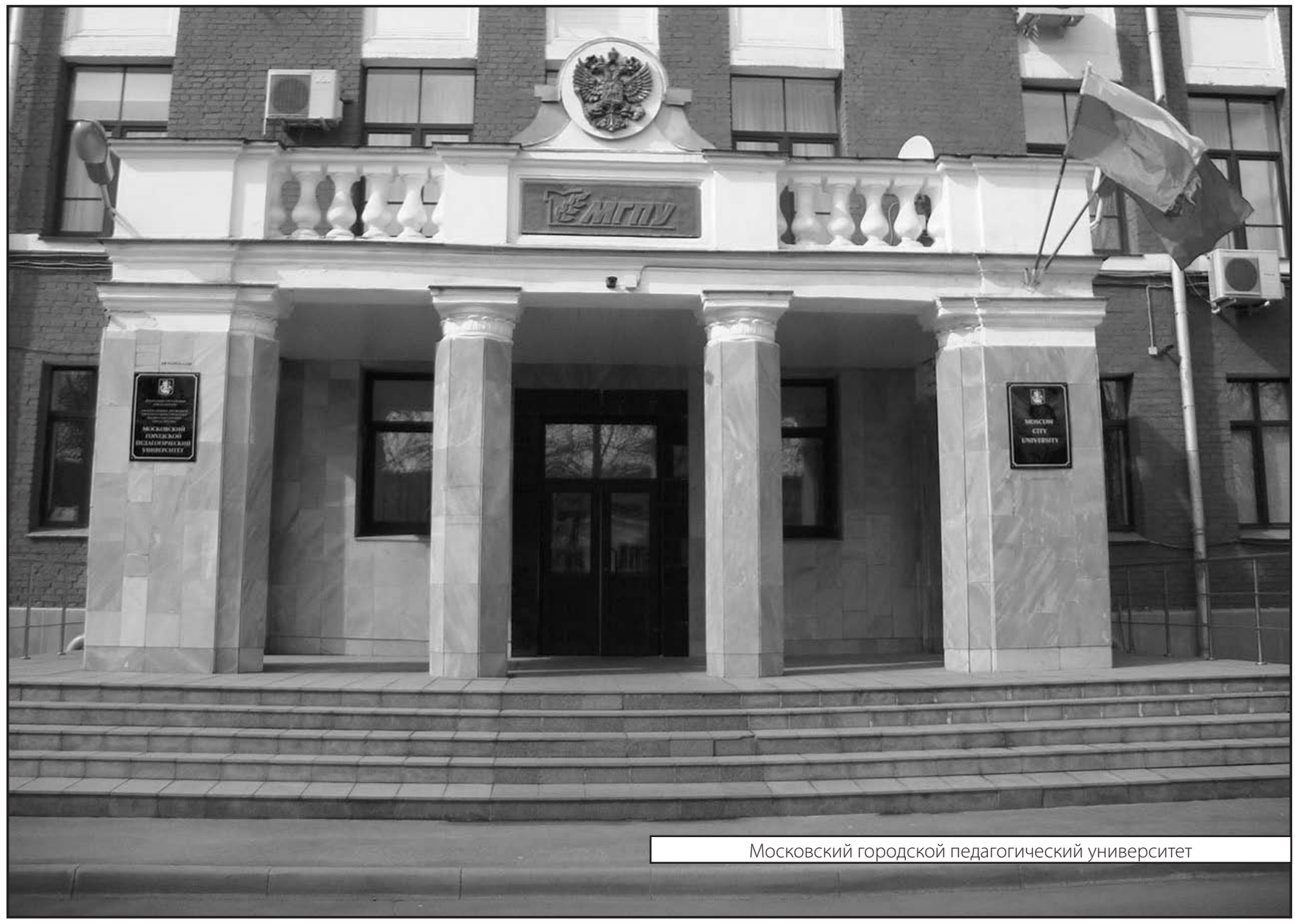

